\title{
Multifactorial theory applied to the neurotoxicity of paraquat and paraquat-induced mechanisms of developing Parkinson's disease
}

\author{
Xiao-feng Zhang ${ }^{1}$, Mark Thompson ${ }^{2}$ and Yi-hua $\mathrm{Xu}^{1}$
}

Laboratory studies involving repeated exposure to paraquat (PQ) in different animal models can induce many of the pathological features of Parkinson's disease (PD), such as the loss of dopaminergic neurons in the nigrostriatal dopamine system. Epidemiological studies identify an increased risk of developing PD in human populations living in areas where PQ exposure is likely to occur and among workers lacking appropriate protective equipment. The mechanisms involved in developing PD may not be due to any single cause, but rather a multifactorial situation may exist where PQ exposure may cause PD in some circumstances. Multifactorial theory is adopted into this review that includes a number of sub-cellular mechanisms to explain the pathogenesis of PD. The theory is placed into an environmental context of chronic low-dose exposure to $\mathrm{PQ}$ that consequently acts as an oxidative stress inducer. Oxidative stress and the metabolic processes of PQ-inducing excitotoxicity, $a$-synuclein aggregate formation, autophagy, alteration of dopamine catabolism, and inactivation of tyrosine hydroxylase are positioned as causes for the loss of dopaminergic cells. The environmental context and biochemistry of $P Q$ in soils, water, and organisms is also reviewed to identify potential routes that can lead to chronic rates of low-dose exposure that would replicate the type of response that is observed in animal models, epidemiological studies, and other types of laboratory investigations involving PQ exposure. The purpose of this review is to synthesize key relations and summarize hypotheses linking PD to PQ exposure by using the multifactorial approach. Recommendations are given to integrate laboratory methods to the environmental context as a means to improve on experimental design. The multifactorial approach is necessary for conducting valid tests of causal relations, for understanding of potential relations between PD and $\mathrm{PQ}$ exposure, and may prevent further delay in solving what has proven to be an evasive etiological problem.

Laboratory Investigation (2016) 96, 496-507; doi:10.1038/labinvest.2015.161; published online 1 February 2016

Parkinson's disease (PD) is a neurodegenerative disorder caused by progressive and substantial loss of dopaminergic neurons with accompanying gliosis in the substantia nigra. There are a number of disorders that share some of the same clinical features as PD; the clinical syndrome is called parkinsonism. ${ }^{1}$ Confirmed cases of PD require corroboration between clinical (ie, resting tremor, bradykinesia, rigidity, and asymmetric onset) and neural-pathological tests. The neuralpathological tests must include the presence of Lewy bodies (LBs) (ubiquitin- and $\alpha$-synuclein-positive cytoplasmic inclusions primarily in the surviving neurons) and depigmentation of the locus ceruleus. ${ }^{2,3}$

The prevalence of PD increases most notably with age, but there is also high risk for carriers of certain genetic mutations; some mutations, such as a triplication in the $\alpha$-synuclein gene, ${ }^{4}$ can even cause PD. The etiology of PD remains elusive and sporadic in many circumstances. However, several important contributing factors have been identified at the sub-cellular level in cases of idiopathic $\mathrm{PD}$, including the excess production of reactive oxygen species (ROS). ${ }^{5}$ Pesticides exposure is implicated as a potential cause in idiopathic PD as exposure into the body leads to biochemical competion within the electron transport chain of the mitochondria and the generation of ROS. Mitochondria are a major source of ROS where $2-4 \%$ of electrons escape under normal conditions, but can increase under stress (such as PQ exposure) or in states of disease. A feedback loop forms as mitochondrial dysfunction is in itself linked to oxidative stress. ${ }^{6}$

The purpose of this review is to make inference on a number of testable hypotheses into the etiology of idiopathic

${ }^{1}$ Department of Health Toxicology, Public Health School, Harbin Medical University, Harbin, China and ${ }^{2}$ DWB Consulting Services, Prince George, BC, Canada Correspondence: Dr X-f Zhang, Department of Health Toxicology, Public Health School, Harbin Medical University, No. 157 Baojian Road, Nangang District, Harbin City, Heilongjiang Province 150081, China.

E-mail: zhanghyd@163.com

Received 4 May 2015; revised 7 October 2015; accepted 12 October 2015 
PD having specific relation to the neurotoxicity and pathogenesis of paraquat (PQ). A large number of epidemiological studies have identified a correlative link between PD and pesticides exposure. Three highly utilized agricultural pesticides: 1. PQ, 2. rotenone, and 3. maneb are the key members implicated with risk and incidence of PD. The idiopathic nature of PD makes the relationship between pesticide exposure, risk, and increase of incidence difficult to interpret despite supporting evidence for the linkage in the statistical meta-analysis of 59 separate studies. There is a doubled risk of developing PD among individuals who have been exposed to pesticides. ${ }^{7}$ However, cross-study results are somewhat inconsistent, which leaves a degree of uncertainty in the divide between correlation and causation. New research continues to find such correlative links, but the multifactorial etiology leaves causation open to investigation. We propose that the inconsistency is due to and an expected outcome of a multiple causal problem.

Since the discovery of PQ in 1955 (ref. 8) its use and applications has extended into agriculture and in other applications, such as preventing the spread of invasive aquatic weeds in different kinds of aquatic systems. PQ ( $N, N^{\prime}$-dimethyl$4,4^{\prime}$-bipyridinium dichloride) is a bipyridyl non-selective contact herbicide and is commonly implicated with the rise and incidence of PD. PQ caught the attention of many researchers because its molecular structure is similar to the neurotoxin 1-methyl-4-phenylpyridinium ion $\left(\mathrm{MPP}^{+}\right)$, the active metabolite of 1-methyl-4-phenyl-1,2,3,6-tetrahydropyridine (MPTP) (Figure 1). An acute and permanent parkinsonian state occurs in drug users who intravenously injected preparations of MPTP. Although PQ causes nigrostriatal damage, its effects are different from those of MPTP. ${ }^{9}$ Furthermore, there is a structural similarity between the two molecules. This is not to be used as a basis to draw inference (induction or deduction) on related cause, because there are fundamental differences in the biochemistry of these molecules. Nonetheless, the biochemical similarity to MPTP sparked interest in the topic and lead to a number of hypotheses being adduced that guided consequent research. The analogy between the two molecules has undoubtedly had an important role in the research. The analogy has motivated inference of a number of hypotheses (abduction) that turned out to be true. Thus analogy with MPTP can be used to adduce new hypotheses provided that the differences are explicitly noted. A key difference between $\mathrm{MPP}^{+}$and $\mathrm{PQ}^{2+}$ (native divalent cation of $\mathrm{PQ}$ ) is charge difference, but $\mathrm{PQ}^{+}$ (mono-cation radical of PQ) is very similar to $\mathrm{MPP}^{+}{ }^{6}$

Our review is broad in scope as we collate evidence of PQ exposure in relation to PD from biochemical pathways, environmental chemistry, and ecotoxicological investigations. There are necessary environmental conditions that must be met if the etiology of PD is caused by PQ exposure. The environmental context is reviewed to determine whether PQ exposure leading to $\mathrm{PD}$ is possible in light of (1) the durability, activity, and breakdown of PQ; (2) exposure

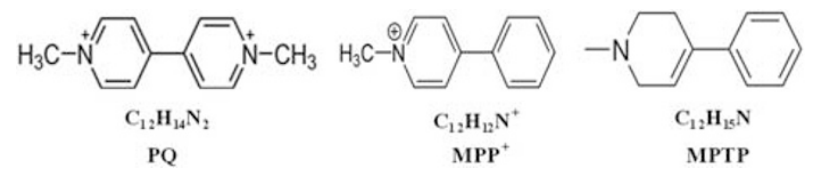

Figure 1 The chemical structure of $P Q, M P P^{+}$, and MPTP.

conditions, and (3) other applicable research into PQ that relates back to environmental health and ecotoxicology that may have bearing on PD. As such, our hypotheses are framed by understanding PD as a multifactorial system of causes; to claim that an effect is caused by a factor or multiple factors means that the cause-effect relation(s) can be explained by adequate or strong inference. ${ }^{10,11}$ This review shows that the relation of $\mathrm{PQ}$ causing $\mathrm{PD}$ is an entangled problem in a network of complex causation involving biochemical and physiological pathways of $\mathrm{PQ}$ that afflicts sub-cellular systems where risk, susceptibility, and expression of the disease is predicated upon the genotype and environment.

\section{PART I: LABORATORY CONTEXT Animal Models}

Chronic exposure to PQ is suspected to cause neurodegeneration in humans and has been experimentally tested in a large number of animal studies. ${ }^{12}$ It is unclear if laboratory-based investigations of $\mathrm{PQ}$ and $\mathrm{PD}$ associations using animal models have reproduced all clinical and pathological features of human PD. Jackson-Lewis et al. ${ }^{13}$ reviewed animal models of PD, including some of the aspects of PQ exposure in rodents. The authors note that laboratory-based administration of PQ can induce 'reduced motor activity and a dose-dependent loss of (tyrosine hydroxylase; TH)-positive striatal fibers and (substantia nigra pars compacta) SNpc neurons' (p. S184); the nigrostriatal (dopamine) system seems to be unaffected in the laboratory animal studies ${ }^{13}$ that were reviewed. However, Jackson-Lewis ${ }^{13}$ exclude results from Yin et al. ${ }^{14}$ who used different genetic strains of mice in their PQ exposure trials, which resulted in increased levels of iron and different gene expression in the ventral midbrain and a loss in dopaminergic neurons in the SNpc. Similarly, Shimizu et al. ${ }^{15}$ found that constant exposure to low levels of PQ affected dopaminergic neurons in the nigrostriatal system of rats. More recently, Pangestiningsigh et al. ${ }^{16}$ report a decrease in the density of catecholaminergic neurons in the SNpc using histochemical preparations from rats subjected to intraperitoneal injection of PQ $(15 \mathrm{mg} / \mathrm{kg})$ over a 6 -week period. ${ }^{16}$

Laboratory investigation into animal models of PD clearly implicates PQ as a dopamine neurotoxin via chronic low-level exposure. For example, intraperitoneal injection of $10 \mathrm{mg} / \mathrm{kg}$ PQ in mice injected at varied intervals for up to 3 weeks cause decreased or altered locomotor activity in conjunction with a number of physiological symptoms occurring in a dose-dependent manner, including significant decline in dopamine levels within the striatum, loss of dopaminergic neurons, degeneration of the nigrostriatal dopamine system, 
aggregate formation in the SNpc containing $\alpha$-synuclein, and formation of LBs. ${ }^{17-19}$

Questions and concerns are commonly raised about extrapolation from experimental animal models to make inferences about the human condition. The clinical and pathological features for PD is reproduced in some animal model studies depending on what genetic strain is being used and other parameters in the experimental design, such as exposure rates, concentrations, and the precision of the methods (eg, gene expression panels, histology, staining, etc.) that is used to measure response effects. What is experimentally measured is also important. The brain is particularly sensitive to oxidative stress and there is a particularly high concentration of iron in the substantia nigra that may make it even more susceptible to free-radical damage. ${ }^{20}$ For example, Yin et al. ${ }^{14}$ measured iron concentrations in the midbrain of susceptible mice strains, which increased neurotoxicity risk via oxidative stress. The iron accumulation has a role in $\alpha$-synuclein protofibril formation and exacerbates a number of neurological effects that models PD neural degeneration symptoms after exposure to the PQ.

Some researchers have questioned the level of risk implicating PQ with PD to suggest that animal models are inconclusive in reference to the human condition of PD. ${ }^{21-22}$ Dauer and Przedborski ${ }^{23}$ make an additional claim that only non-human primates could accurately mimic the motor symptoms of PD. However, these views are presented under a views are presented under a unifactorial approach to epidemiology. Applying a simple hypothesis to a multifactorial problem delays progress in understanding the etiology and development of applicable tests; for example, this type of approach significantly delayed understanding the etiology of atherosclerosis. ${ }^{10}$

\section{The Comparative Approach}

McWhite et al. ${ }^{24}$ provide a recent review on the comparative approach and its application to human disease research, including advances in technique that can be used to elucidate and understand PQ neurotoxicity. The multifactorial approach is complementary to the comparative approach. The inability to fully express all features of human PD in animal models is an expectation of the multifactorial and comparative approach. Variations of expression are a consequence of evolutionary divergence and environmental context. Noted variations and difference in response can assist in the elucidation of physiological sub-cellular mechanics that may be involved. Including different and diverse species in experimentation is not only relevant to $\mathrm{PQ}$ and $\mathrm{PD}$ relations, but broadening the research to include a larger myriad of species via the comparative evolutionary approach has proven more effective in elucidating our understanding of life sciences generally with proven applications to human health. There are structural analogs and homologs that make the comparative approach applicable to such experimentation. For example, there may be structural analogies in insects, such as tight and pleated-sheet septate junctions between neurons, glial, and perineural cells that might have a similar function to the blood-brain barrier (BBB) in mammals. ${ }^{25}$ The comparative approach increases the potential for developing innovative experimental design and understanding of $\mathrm{PQ}$ biochemistry in vitro. This knowledge also extends to environmental health more generally, which is the approach taken herein as we first review hypotheses involving molecular pathways that have been elucidated from comparative studies and consider the implications of these in a broader environmental context.

\section{PQ Induces Oxidative Stress and Inhibits Mitochondrial Complex I Activity}

The metabolic activity of mitochondrial complex I (also named as $\mathrm{NAD}(\mathrm{P}) \mathrm{H}$ dehydrogenase) decreases in the substantia nigra of patients who developed PD through accidental exposure to MPTP. A specific defect in complex I activity was identified in patients who died with idiopathic $\mathrm{PD}$, which is reproduced in laboratory studies of animals administered MPTP. ${ }^{26,27} \mathrm{We}$ adduce that PQ neurotoxicity similarly lowers activity of mitochondrial complex I in the substantia nigra. This inference is supported by the experimental evidence that reveals PQ cytotoxicity acts directly on mitochondrial complex I to induce mitochondrial cytopathy. ${ }^{28}$

Mitochondrial complex I oxidizes $\mathrm{NAD}(\mathrm{P}) \mathrm{H}$ to $\mathrm{NAD}(\mathrm{P})^{+}$by transferring electrons to ubiquinone in the electron transport chain. The presence of $\mathrm{PQ}^{2+}$ disrupts the oxidation of $\mathrm{NAD}(\mathrm{P})$ $\mathrm{H}$ by accepting electrons to form $\mathrm{PQ}^{+}$through $\mathrm{NAD}(\mathrm{P}) \mathrm{H}-$ cytochrome $\mathrm{P} 450$ reductase, which ultimately inhibits the natural function of complex I (Figure 3). $\mathrm{PQ}^{+}$spontaneously accepts an electron from the reductant, reacts with oxygen, and generates the superoxide radical $\left(\mathrm{O}_{2}^{-}\right)$as $\mathrm{PQ}^{+}$oxidizes back into $\mathrm{PQ}^{2+}$; this reduction-oxidation cycle is repeated by the same $\mathrm{PQ}^{2+}$ molecule. The reactive $\mathrm{O}_{2}{ }^{-\cdot}$ sets off well-known cascade of reactions generating other ROS, such as hydrogen peroxide $\left(\mathrm{H}_{2} \mathrm{O}_{2}\right)$ and the hydroxyl radical $\left(\mathrm{OH}^{-}\right) \cdot{ }^{29-30}$ These ROS are generated from PQ competing for electrons in the cellular-based redox cycle, which changes the redox environment, causes mitochondrial dysfunction (such as mitochondrial depolarization), and leads to the consequent apoptosis of dopaminergic cells in a stepwise manner. This process is hypothesized to cause the onset of PD (Figure 2).

The overexpression of manganese superoxide dismutase, a mitochondrial antioxidant enzyme located in the mitochondrial matrix, markedly reduces the level of oxidative stress and cell death, but does not prevent the loss of the mitochondrial membrane potential. ${ }^{31}$ This demonstrates that PQ-induced toxicity is related to mitochondrial superoxide. We do not describe in detail how PQ induces apoptosis of neurons, because the intrinsic apoptotic pathway of PQ-induced apoptosis is the same for most toxicants as reported. The inference is supported by the evidence that PQ induces an increase in ROS and oxidative stress in both the cytosol and 


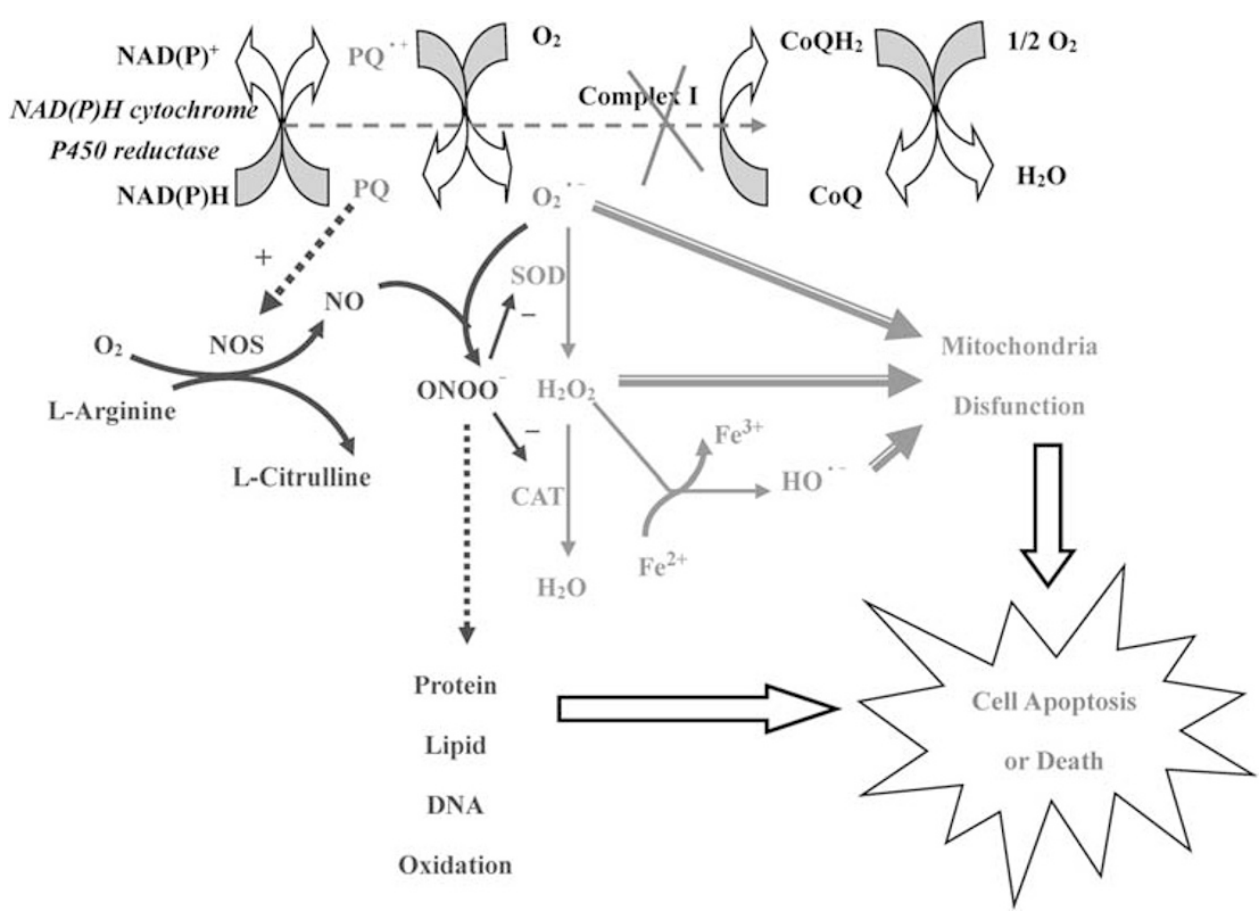

Figure 2 A schematic representation of $P Q$-induced oxidative stress. $P Q$ is reduced to $P Q^{+}$by $N A D(P) H-c y t o c h r o m e ~ P 450$ reductase, and thus inhibits complex I activity. In the presence of oxygen, $\mathrm{PQ}^{+}$is oxidized with $\mathrm{O}_{2}^{-\cdot}$ production. $\mathrm{O}_{2}^{-{ }^{-}}$is metabolized to $\mathrm{H}_{2} \mathrm{O}_{2}$, and $\mathrm{OH}^{-}$successively, causing mitochondria dysfunction alone and/or together and leading to apoptosis or death of neurons. Moreover, $\mathrm{PQ}$ promotes $\mathrm{NO}$ generation by activating $\mathrm{NO}$ synthase. $\mathrm{NO}$ reacts with $\mathrm{O}_{2}^{--}$to generate $\mathrm{ONOO}^{-}$, which oxidizes proteins, lipid, and DNA, resulting in cell apoptosis and death.

mitochondrial matrix of dopaminergic cells prior to cell death. ${ }^{31}$

Several recent studies have identified a lack of complex I inhibition following PQ exposure, suggesting that complex I might not be the essential target. However, the potential for PQ-induced dopaminergic neurons death remains. Moreover, PQ can induce neurotoxic effect without complex I inhibition. ${ }^{32,33}$ It is known that PQ-induced decrease of complex I activity precedes respiratory dysfunction in the brain. Complex I activity decreases significantly in rat brains $2 \mathrm{~h}$ after PQ administration. ${ }^{34}$ Furthermore, PQ leads to the production of ROS within the complex III electron transport chain, which has been elucidated in the Drosophila model system. ${ }^{35,36}$

Cytochrome P450 enzymes and their isoforms metabolize and can inactivate neurotoxic compounds in the brain. Cytochrome P450 enzyme may have an important role in the bioactivation of $\mathrm{PQ}$, but a comprehensive understanding into this relationship is lacking except to note that genetic variants of the P450 enzymes show different levels of susceptibility developing PD. ${ }^{37}$ Cytochrome $\mathrm{P} 450$ reductase is a diaphorase enzyme that can transfer electrons from $\mathrm{NAD}(\mathrm{P}) \mathrm{H}$ to $\mathrm{PQ}$. Cytochrome P450 enzyme concentrations are lower in the brain than in other tissues, but they are also localized in selective cell populations. ${ }^{38}$ Other enzymes capable of initiating the metabolism of $\mathrm{PQ}$, which are applicable to its oxidative stress, induced toxicity include nitric oxide synthase (NOS), thioredoxin reductase, and NADPH oxidase (NOX). ${ }^{32,39}$

\section{PQ Activates NOS}

NOS participates in PQ-induced lung injury. ${ }^{40}$ Similarly, there is the potential for PQ inducing the production of nitric oxide (NO) in the brain by inducing NOS activity. ${ }^{41}$ Once NOS is activated, NO forms the toxic peroxynitrite anion $\left(\mathrm{ONOO}^{-}\right)$in reaction with $\mathrm{O}_{2}^{-}$(Figure 2). The process continues as $\mathrm{ONOO}^{-}$oxidizes proteins, lipids, and DNA, which damages their structure and function resulting in the apoptosis and/or cell death. Concurrently, $\mathrm{ONOO}^{-}$also inhibits the antioxidant activities of some enzymes, which in turn leads to the increase of $\mathrm{O}_{2}^{-\cdot}$ and $\mathrm{ONOO}^{-} .{ }^{42}$ In addition, PQ generated $\mathrm{O}_{2}^{-\cdot}$ by NOS as an electron source at the expense of NO formation. ${ }^{40}$ These findings add support to the hypothesis that increased extracellular dopamine release and/or death of the dopaminergic neurons could be inhibited by the inhibitors of NOS. ${ }^{15}$

\section{PQ Activated Microglial NADPH Oxidase 2}

PQ increases ROS production in microglia by activating microglial NOX2, but this does not occur in neurons. Lower doses $(0.5 \mu \mathrm{M}$ and $1.0 \mu \mathrm{M})$ of $\mathrm{PQ}$ activates changes to the microglial morphology and significantly increases NOX2 expression, which results in dose-dependent $\mathrm{O}_{2}{ }^{-\cdot}$ production. ${ }^{32,43,44}$ The depletion of microglia from 
neuron-glia cultures and genetic deletion of NOX2 blocks PQ-induced neurotoxicity. ${ }^{43,44}$ These results implicate microglial NOX2 as an essential factor mediating neurotoxicity triggered by $\mathrm{PQ}$ exposure. However, it is not known where PQ-induced $\mathrm{O}_{2}{ }^{-\cdot}$ is generated within the microglia that would result in the damage of surrounding neurons.

One hypothesis is that PQ could gain entry to microglia, presumably by active transport, to initiate the redox-cycling $\mathrm{O}_{2}-\cdot$ production. However, this contradicts the reports that PQ causes extracellular $\mathrm{O}_{2}-\cdot$ production from microglia. ${ }^{32,43}$ A second hypothesis holds that PQ remains extracellular relative to the microglia and could take the electron transferred across the membrane from NOX2 before it interacts with oxygen to produce extracellular $\mathrm{O}_{2}{ }^{-}$at more efficient and faster rates when compared with the NOX2 enzyme complex alone. ${ }^{45} \mathrm{~A}$ third hypothesis is that PQ activates NOX2 through common intracellular signaling to cause the assembly of the entire NOX2 enzyme complex. This could serve as a base signal that would be amplified by the extracellular redox signaling proposed in the second hypothesis. ${ }^{45}$ None of these hypotheses have been tested. Although it is clear that PQ converges on the final pathway of NOX2-mediated ROS production in microglia, the molecular mechanisms triggering NOX2 activation remain poorly understood.

\section{PQ Contributes to Alterations in Energy Metabolism}

PQ exposure induces alterations in the pentose phosphate pathway metabolome. The ensuing increase in metabolites, such as glucose-6-phosphate, fructose-6-phosphate, and glucono-1,5-lactone, leads to an increase in NADPHreducing equivalents and stimulates $\mathrm{PQ}$ redox cycling, oxidative stress, and cell death. PQ-induced alterations in energy metabolism could significantly contribute to dopaminergic cells death progression. ${ }^{46}$

\section{PQ Passes Through the BBB}

Some studies have concluded that PQ is an unlikely candidate for dopaminergic neurotoxicity owing to its low partition coefficient, limited absorption, and poor penetration across BBB. ${ }^{47-49}$ However, the BBB is not entirely impenetrable and its state of function depends upon a number of factors, including depression that modulates glial cell line-derived neurotrophic factor, ${ }^{50}$ viruses that can disrupt and cleave tight junctions, ${ }^{51}$ and by several neurological disorders. ${ }^{52}$

The brain's endothelial cells also have an increased density of mitochondria that can increase the risk of ROS formation. ${ }^{53}$ Oxidative stress damaging the endothelial cells of the BBB increases its permeability. ${ }^{52}$ Recent studies also report that PQ can cross the BBB in the mice and rats. ${ }^{9}$ Kuter et $a l .{ }^{54}$ report increased ROS production in the brain after repeated low-dose PQ exposure in rats that 'can cause slowly progressing degenerative processes, without the toxic effects in the peripheral tissues' (p. 1121). Microglia also have important implications in $\mathrm{PQ}$ transport through their relations to the $\mathrm{BBB}$. Rappold et al. ${ }^{55}$ introduce a biochemical model involving microglia for uptake of PQ into dopaminergenic neurons. This process entails the reduction of $\mathrm{PQ}^{2+}$ to $\mathrm{PQ}^{\bullet+}$ 'by enzymes, such as NOX on microglia'. Once in contact with the microglia, the cation $\mathrm{PQ}^{\bullet+}$ gains access to the dopamine transporter (DAT).

Other multifactorial vulnerabilities are likely to exist, such as increasing risk of permeability across the BBB via brain injury or genetic factors. For example, Bartels et al. ${ }^{56}$ found elevated passage levels of [11C]-verapamil across the BBB in patients carrying a gene for reduced levels of P-glycoprotein, a molecular efflux pump. Although the effect of this gene has not been tested in relation to PQ permeability across the BBB, the implication is intriguing because experimental induction of P-glycoprotein synthesis leads to a decrease in the accumulation and consequent toxicity of $\mathrm{PQ}$ in the lungs. ${ }^{57}$ Once PQ is able to pass the BBB, it is able to enter the neutral amino-acid transport system and subsequently transport into neuronal cells in $\mathrm{a} \mathrm{Na}^{+}$-dependent manner where it persists in the midbrain with a half-life of $\sim 3$ weeks in mice; the half-life of PQ in the mouse brain varies according to the strain. ${ }^{58-60}$

\section{PQ Induced Excitotoxicity}

Glutamate (Glu) is the most important excitatory neurotransmitter in CNS. Under normal conditions, pre-synaptic neurons release Glu into the synaptic cleft upon being stimulated. Astrocytes take up Glu through excitatory aminoacid transporters, where Glu is converted into nontoxic metabolite glutamine (Gln) ${ }^{61}$ However, increased concentration of Glu in the synaptic cleft causes excitotoxicity. The excitotoxicity increases calcium influx and overload in the post-synaptic neurons, which leads to an increased production of $\mathrm{ROS}$ and $\mathrm{ONOO}^{-}$, mitochondrial dysfunction, continuous and long-lasting dopamine overflow, as well as cells apoptosis or death. ${ }^{62} \mathrm{PQ}$ may contribute to excitotoxicity by activating $N$-methyl-D-aspartate receptors, a subtype of Glu receptors, resulting in oxidative stress as a source of ROS. ${ }^{63}$ In turn, increased ROS may also exacerbate subsequent excitotoxicity by decreasing the uptake capacity of Glu, inhibiting the activity of Gln synthase in the affected astrocytes, and cause neuronal cell death (Figure 3).

\section{PQ Might Involve Dopamine Catabolism}

PQ neurotoxicity may be associated with the oxidative pathway of dopamine catabolism. Kang et al. ${ }^{64}$ found that PQ administration affected the pathway of dopamine catabolism in vivo, decreases in dopamine and homovanillic acid (HVA) concentrations, and no concentration change of 3,4-dihydroxyphenylacetic acid (DOPAC), but no explanation was provided. Dopamine catabolism can produce HVA through $\mathrm{N}$-oxidative deamination by monoamine oxidase B to form 3,4-dihydroxyphenylacetaldehyde (DOPAL), which is subsequently oxidized by aldehyde dehydrogenase (ALDH) into DOPAC (Figure 4) ${ }^{65}$ Previous studies show that lipid peroxidation products potently inhibit ALDH to yield 


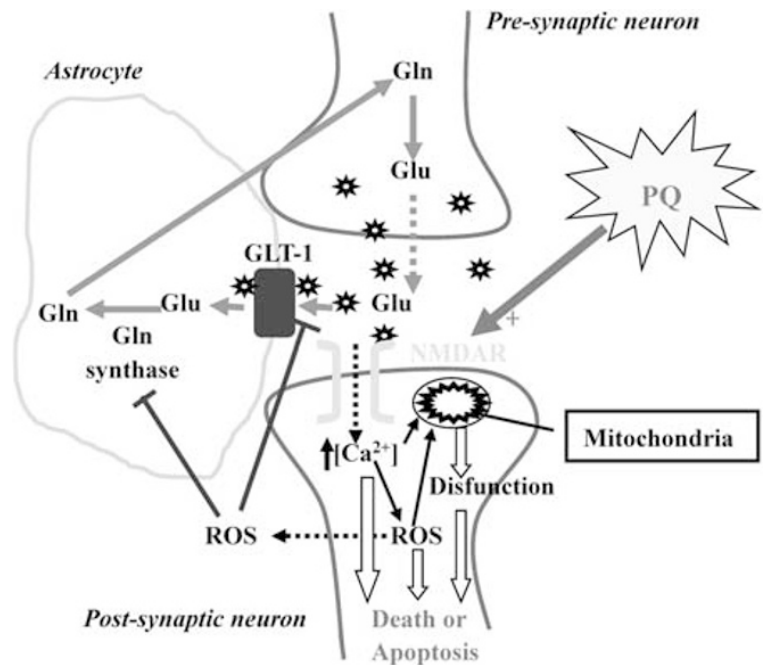

Figure 3 A schematic of $P Q$ inducing excitotoxicity. $P Q$ induces activation of NMDA receptor, resulting in increasing concentration of intracellular calcium and ROS generation, thus damaging mitochondria function, finally leading to neural apoptosis and death. In parallel, ROS exacerbates excitotoxicity through enhanced efflux of Glu from rich intracellular sites, inhibition of Glu uptake and Gln synthase activity.

aberrant levels of DOPAL, which creates a reactive environment and causes protein modifications. ${ }^{66}$

The cytotoxicity of DOPAL is implicated as one of the strongest in dopamine-derived metabolites. It is an endogenous neurotoxin and is considered as a factor in PD-related neuronal degeneration. ${ }^{67} \mathrm{PQ}$-induced oxidative stress can cause the generation of lipid peroxidation products (such as malondialdehyde). 68,69 Hence, we hypothesize that PQ exposure affects dopamine catabolism by inhibiting ALDH and elevating DOPAL levels. In this process, DOPAL might act as a neurotoxin causing damage and death of dopaminergic neurons.

\section{PQ Induces $a$-Synuclein Aggregation}

Genome-wide studies have identified genes encoding for $\alpha$-synuclein as a key risk factor in the development of PD. The $\alpha$-synuclein pre-synaptic protein is a component of LBs that acts as negative regulator of dopaminergic neurotransmission. PQ increases $\alpha$-synuclein production and accelerates the rate of aggregate formation containing $\alpha$-synuclein in the substantia nigra of mice. Overexpression of $\alpha$-synuclein in transgenic mice protects against neurodegeneration induced by $\mathrm{PQ} .{ }^{18,70}$ In vitro studies indicate that PQ markedly accelerates the formation of $\alpha$-synuclein fibril in a dose-dependent fashion. ${ }^{71}$ Kumar et al. ${ }^{72}$ detected the formation protein radicals as an initiating mechanism in the aggregation $\alpha$-synuclein. Moreover, NOX and inducible NOS were involved in $\mathrm{ONOO}^{-}$-mediated protein radical formation and subsequent neuronal death in the midbrains of PQ- and maneb-coexposed mice. These results implicate PQ-induced upregulation of $\alpha$-synuclein and ROS production as likely mechanisms in various neurodegenerative disorders, including PD.

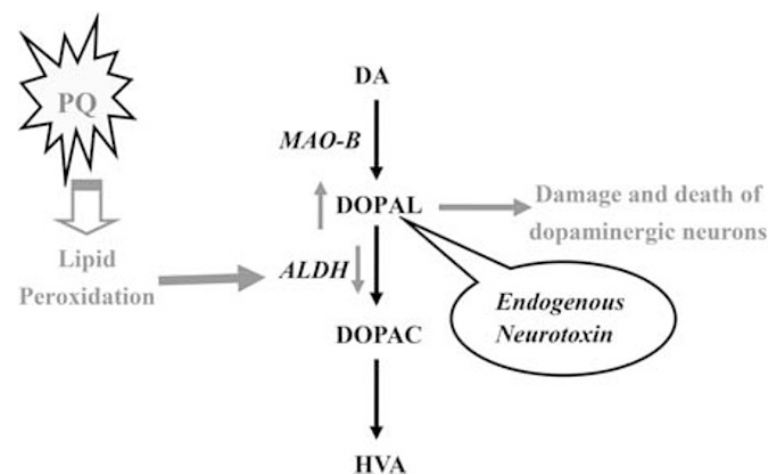

Figure 4 A schematic of the hypothesis that $P Q$ affects dopamine catabolism. PQ-induced lipid peroxidation products inhibit ALDH activity, resulting in increasing concentration of DOPAL, which is a reactive endogenous neurotoxin and leads to death of dopaminergic neurons.

\section{PQ Induces Autophagy}

Autophagy is inferred to have an etiological association with neurodegenerative diseases. The reduction of cytoplasmic inclusions by autophagy may be a protective adaptation against neurodegenerative disease. Gonzalez-Polo et al. ${ }^{73,74}$ demonstrated that low concentration of PQ $(10 \mu \mathrm{M})$ produced the characteristics of autophagy in neuroblastoma SH-SY5Y cells, such as degradation of oxidized proteins and damaged or dysfunctional cytoplasmic inclusions. They infer that PQ-treated cells triggered autophagy as a defense mechanism for neuronal survival. Inhibition of lysosomal hydrolases also increases PQ toxicity and autophagy protein 5 -dependent autophagy acts as a protective mechanism in dopaminergic cells during apoptotic cell death induced by PQ. ${ }^{75}$ Hence, it is thought that autophagy is not a type of cell death in this case. The inhibition of autophagy accelerates PQ-induced apoptosis, owing to insufficient clearance of cytoplasmic inclusions and dysfunctional mitochondria, finally to result in cells loss. ${ }^{73,74}$ Likewise, excessive activation of autophagy can result in neuronal death. PQ may trigger the activation of autophagy in neurons by creating an early endoplasmic reticulum stress response, which activates apoptosis signal-regulating kinase 1, a member of mitogenactivated protein kinase family. ${ }^{76}$ The exact mechanism involved in PQ-induced autophagy and its relation with neuronal cells death or survival is not fully understood.

\section{PQ Inactivates TH}

$\mathrm{TH}$ is a rate-limiting enzyme in dopamine synthesis and its expression is decreased in relation to dopaminergic neurons loss. Exposure to MPTP, for example, causes the loss of TH activity, the impairment of dopamine synthesis, and decreased dopamine levels in the striatum. ${ }^{77}$ Similarly, numbers of TH-positive neurons in the substantia nigra decrease markedly in mice receiving oral treatments of $\mathrm{PQ}{ }^{78}$ It is inferred that $\mathrm{PQ}$ might inactivate $\mathrm{TH}$ by producing reactive nitrogen species and subsequently induce tyrosine nitration. For example, catalytic activity of TH is inhibited by exposure 
to $\mathrm{ONOO}^{-}$, which results in extensive tyrosine nitration. ${ }^{79}$ The implication of $\mathrm{PQ}$ afflicting $\mathrm{TH}$ regulation in the pathophysiology of $\mathrm{PD}$ is an intriguing hypothesis that requires further studies.

\section{PART II: ENVIRONMENTAL CONTEXT}

The neurotoxic effects of PQ may be enhanced by synergistic interaction with other environmental contaminants, age or behaviour of individuals being exposed, and interrelated genetic factors. In humans, PQ can be absorbed by oral intake, inhalation, and bruised or irritated skin. Once absorbed through the skin, PQ is distributed to all areas of the body accumulating at varying concentrations. It tends to concentrate in the lungs, which is the reason that acute exposure to PQ causes pulmonary lesions in humans. ${ }^{80}$ Clinical symptoms from direct exposure to $P Q$ are well known. What is less understood is the impact from chronic low-dose exposure, which is the type of exposure that is hpothesized between PQ and PD. Some of the laboratorybased animal studies that were reviewed earlier may be testing PQ exposure at higher doses and over shorter terms than would be expected in natural occupational settings. Moreover, the intraperitoneal injection routes generally used for laboratory-based administration are unlikely to be experienced by actual pesticide users. One hypothesis we present in this context is that there are multiple avenues for chronic low-dose exposure of PQ through the environmental context.

The environment provides the critical context for understanding PQ exposure routes and potentials for duration of exposure in relation to human health. The environment is critically important for etiological investigation into the potential of PQ causing PD as $<0.1 \%$ of pesticide field applications reach the intended target. ${ }^{81}$ Moreover, as PQ is one of the most widely used herbicides in the world it is all the more important to understand its trajectory and effect after being released into the environment. A key problem for elucidating the etiology of PD and other neurodegenerative diseases in relation to pesticide exposure is that it is a multifactorial problem. ${ }^{82}$

\section{PQ Released in the Environment}

PQ is absorbed quickly by leaves of plants after it is applied by spraying. Once in the leaf, it competes with and accepts electrons from photosystem I, which inhibits photosynthesis. PQ does not affect all plants equally. Bark inhibits entry so it does not kill larger plants having secondary growth. It does not kill roots or rhizomes, ${ }^{8}$ but there can be uptake of PQ through the soil by some plant roots. ${ }^{83}$ Slade ${ }^{84}$ concluded that PQ moves through the xylem toward the roots of plants with only minor residues ('on the order of $0.06 \mathrm{ppm}$ ') being detected in harvested tubers. Metabolic degradation of PQ does not occur in the plant itself and photochemically degraded products also go undetected. It is also toxic to soil bacteria and fungi. ${ }^{85}$

\section{PQ Degradation}

Ultraviolet light and sunlight degrades PQ into six organic intermediate products with complete degradation after $12 \mathrm{~h}$ of irradiation. It completely mineralizes $\left(\mathrm{H}_{2} \mathrm{O}+\mathrm{CO}_{2}+\right.$ $\mathrm{NH}_{4}+/ \mathrm{NO}_{3}{ }^{-}$) within a few hours of coming into contact with air. ${ }^{86,87}$ However, the photocatyltic process also requires the presence of oxygen. ${ }^{88}$ Early studies indicated minimal environmental impact to aquatic ecosystems and only shortterm persistence in the water column, but long-term persistence (364 days) in the soil ${ }^{89}$ half-lives of PQ from 16 months up to 13 years have been reported. ${ }^{81,90} \mathrm{PQ}$ is strongly absorbed onto clay particles where it becomes inactive ${ }^{84}$ For example, vegetation can germinate normally when grown in soil contaminated with $\mathrm{PQ}$ residue. ${ }^{89}$ However, the retention, degradation, and mobility of PQ within soil is dependent upon a number of biochemical and physical factors in the soil itself, namely $\mathrm{pH}$ and ionic strength. ${ }^{91}$ Microbial degradation of $\mathrm{PQ}$ is also involved in the lifespan, mobility, and potential environmental impacts of PQ. ${ }^{85}$ Furthermore, some of the photocatalytic degradation products may be genotoxic. ${ }^{8}$

\section{Environmental Mobility of PQ}

The fact that PQ is rapidly and strongly bound to clays and soil organic matter with minimal leaching has been the basis for the conclusion that it is relatively inert after its use and application. ${ }^{8,81,92}$ However, the solubility, mobility, and environmental chemistry of PQ is dependent upon the types of soils in the receiving environment and the associated chemistry of the soil, as it can compete with other cations raising the risk of contamination by release of other metals. ${ }^{91,93}$ The level of PQ absorption into soils also tends to decrease as the ratio of soil to water increases. ${ }^{83}$ Although PQ becomes tightly bound to clay particles and rapidly degrades when exposed to light, it is soluble and can remain active and mobile in water. ${ }^{94}$ The solubility of PQ increases risk of water contamination.

PQ has been detected in surface water, drinking water, and in food supplies. ${ }^{94-96}$ For example, concentrations of PQ ranging from $4.0 \mu \mathrm{g} / \mathrm{l}$ to $87.0 \mu \mathrm{g} / \mathrm{l}$ occur in ground and surface water in Spain and Thailand. ${ }^{94}$ Water is a vector for exposure, sorption, and bio-accumulation within the tissues of aquatic organisms. Exposure to PQ induces stress and mortality on some species of fish, amphibians, earthworms, and other organisms. ${ }^{96-101}$ Ghose et al. ${ }^{102}$ list PQ as one of the most toxic herbicides for amphibians, which is a serious ecotoxicological concern in relation to global and precipitous declines in this class of vertebrates. Studies into the exposure and response to PQ in fish, amphibians, and insects demonstrate the process whereby the ROS induce a physiological response of increasing antioxidant enzymes; ${ }^{97}$ this is an example of the comparative method revealing ROS physiological response in other lineages. Although environmental stress is a concern, the accumulation of PQ into the tissues of organisms may present another vector for exposure. 


\section{$P Q$ in Animal Tissues}

The United States Environmental Protection Agency reported on a number of experiments on administering PQ and following the trajectory along with secondary compounds, which accumulated in the tissues of farm animals (cows, goats, pigs, and poultry) and rats. Although a large percentage of PQ is excreted through the feces, PQ residues accumulate in the animal tissues. ${ }^{103}$ International food markets make use of many different types of exotic meats, such as reptiles and amphibians, where little is known on the sorption of PQ. There may be a risk of trophic accumulation of PQ owing to its accumulation in animal tissues, ${ }^{96}$ which could also add to its mobility through ecosystems and possibly back into human populations via food markers. ${ }^{104}$

\section{Multifactorial Cause}

Like others, ${ }^{105-107}$ we conclude that the relationship between $\mathrm{PQ}$ and PD is a multifactorial problem. This requires a different theoretical and methodological approach for experimentation and understanding of $\mathrm{PQ}$ exposure and its involvement with PD. It is questionable if the genetic and environmental conditions necessary to test the multifactorial hypothesis of PD via PQ exposure can be wholly accomplished by simple animal model experimentation. However, all available relevant evidence must be taken into consideration. ${ }^{108}$ Innovative laboratory methods may be used to recreate the conditions identified in the field, such as use of different genetic strains, head trauma-related risk, and variations on long-term low-dose exposure through varied exposure routes. A key conclusion that can be reached from the multitude of investigations into the relations between PD and its causes is that the research is made more complex by the multiplicative environmental and genetic factors that are involved. ${ }^{109,110}$ Combination of exposure to multiple environmental pollutants also needs to be factored into the multifactorial experimental process.

\section{Synergistic Effects}

Combined exposure of PQ with other substances creates a synergistic effect and induces a full range of PD clinical features in animal models. For example, combined exposure of $\mathrm{PQ}$ with maneb decreases expression of striatum $\mathrm{TH}$, alters states in the dopaminergic neurons transporter, alters motor activity, increases dopamine accumulation in the synaptosome, and alters dopamine levels and metabolites in the striatum. ${ }^{111}$ The combined effect of PQ and maneb is evident even among people having residences near fields that have been treated. ${ }^{112} \mathrm{~A}$ particular risk is also identified by exposure to a combination of PQ and maneb when exposed at a younger age. ${ }^{22}$ Organophosphates, which can be combined with PQ (eg, organophosphate PQ is produced commercially Gramoxone), are also implicated in increasing risk of PD. ${ }^{113,114}$ There may also exist a positive association between fungicide benomyl and the risk of developing PD. ${ }^{115,116}$ Likewise, Mangano and Hayley ${ }^{117}$ found that inflammatory priming of the dopamine neurons with an inflammatory agent altered the effects of PQ exposure.

\section{Genetic Factors}

Genetic factors are importantly implicated in the multiplicative pathology of PD. ${ }^{109}$ The combined effect of PQ, maneb, and genetics (DAT locus variants) increases risk of PD incidence three- to fourfold, whereas the same adverse effect was not identified when PQ or maneb were used in isolation. ${ }^{118,119}$ In human populations, individuals with homozygous deletions of the genes encoding glutathione S-transferase T1 also might be at high risk of developing PD from PQ. ${ }^{106}$ Genes that have been identified and implicated in changing the susceptibility of developing PD include those that encode for a-synuclein, parkin, and dardarin; ${ }^{120}$ Parkinmediated TNF- $\alpha$ receptor-associated factor $2 / 6$ suppression is also differentially expressed in human $\mathrm{PD}$ tissues and applicable to apoptotic pathways. ${ }^{121}$ Shulman et al. ${ }^{122}$ provide a comprehensive review many of PD and genetics.

\section{Human Exposure to $\mathbf{P Q}$}

$\mathrm{PQ}$ is used in over 130 countries worldwide, including China, Japan, Africa, Malaysia, South America, and India. There is a large number of $\mathrm{PQ}$ deaths involving suicide by lethal ingestion, ${ }^{123}$ but occupational associated ailments and mortality are also known to occur ${ }^{124}$ with rates varying by nation and associated demographics. For example, respiratory problems (chronic cough or dyspnea, breathlessness, and wheezing) are associated with dose-dependent and increasing length of exposure to $\mathrm{PQ}$ through its applied use in agriculture. ${ }^{125}$ The lethal aspect to $\mathrm{PQ}$ has led to stringent regulations in $>30$ countries worldwide. ${ }^{124}$ For example, $\mathrm{PQ}$ is banned in the European Union since 2007 and currently under restricted use in the United States. Nonetheless, PQ continues to be used extensively and its rate of use is rising in developing countries as demographics are changing from rural to urban and demands on agriculture are increasing as population numbers go up.

Although proper use of personal protective equipment (PPE) leads to a reduction in the measured incidence of $\mathrm{PD}$ associated with use of $\mathrm{PQ}^{126}$ there is a dilemma ${ }^{127}$ whereby education for safe application may be lacking, funds may be unavailable or cultural differences may even discourage the use of PPE in developing countries. Although high-dose PQ exposure is not a likely cause of $\mathrm{PD},{ }^{128,129}$ there may be a causal relationship between $\mathrm{PQ}$ and $\mathrm{PD}$ through chronic low-dose exposure. The environmental context presents this type of scenario, but more research is needed to understand the avenues for exposure that are introduced in this review.

\section{Risk of Developing PD with PQ Exposure}

Concern over potential relations between $\mathrm{PQ}$ and increasing incidence of PD received greater attention following publication of a research in the 1990s that looked into 120 cases of PD in Taiwan and identified increasing risk and incidence of $\mathrm{PD}$ that corresponded to increasing duration of PQ exposure. 
If no relation exists between PD and PQ exposure, then zero rise in incidence of PD would be expected in areas where it is being used. However, a 4.7 -fold increase in PD by PQ exposure and $6 \times$ increased risk for individuals exposed to PQ for $>20$ years was identified. ${ }^{130}$ In 2013, a meta-analysis from 104 prospective cohort and case-control studies supported previous findings that exposure to pesticides was a risk factor for developing PD, and PQ exposure was associated with about twofold increase in risk of PD. ${ }^{131}$ Exposure to $\mathrm{PQ}$ within $500 \mathrm{~m}$ of the home increased PD risk by $75 \%$ (CI: 1.13-2.73). ${ }^{132}$ Lee et al. ${ }^{133}$ reported that the risk of developing PD was threefold higher in individuals exposed to PQ who suffered traumatic brain injury.

\section{CLOSING}

The synthesized review of research into PQ and PD relations identifies $\mathrm{PQ}$ as a strong oxidative stress inducer that participates in the formation of ROS. The pathogenesis of $\mathrm{PQ}$-induced $\mathrm{PD}$ is a multifactorial problem involving chronic low-dose exposure, oxidative injury by inducing the increased production of ROS in the mitochondria. This process causes loss of dopaminergic neurons in animal models through a number of biochemical pathways that we have identified and hypothesized in our review (Figures 2,3,4). $\alpha$-synuclein aggregation formation, abnormality of dopamine catabolism, and autophagy can directly or indirectly contribute to the pathogenesis of $\mathrm{PD}$ in relation to $\mathrm{PQ}$ under exacerbated conditions of oxidative stress. The production of $\mathrm{O}_{2}^{-}$via redox cycling in the neurons is inferred as a the key mechanism in our hypotheses, implicating PQ as a redox active compound that can eventually cause apoptosis of dopaminergic cells.

Like Goldman, ${ }^{134}$ our review identifies consistency among studies that span the gambit of investigations into cellular processes, model organisms, and human populations in context of PD pathogenesis. The multifactorial approach is essential for understanding this problem. Future experimental and inferential development of this theory may be delayed without applicable tests. The significance of meta-analysis indicating higher incidence of PD development in areas subject to PQ exposure (eg, farmland and use in undeveloped nations) requires explanation. The environmental context to PQ shows that environmental chemistry, human demographics, genetics and other factors, such as the use of PPE, all have a role to play in relation to human health and the experimental process for testing PQ to PD relations.

The synergism of effect from exposure to multiple environmental agents of magnifies the complexity of analysis, but it also puts populations at greater risk. For example, PQ interaction with other metals in soils ${ }^{91,93}$ may be an overlooked factor as metals and other environmental agents are known to cause nigrostriatal damage. ${ }^{120}$ The mobility and persistence of PQ through ecosystems may introduce small yet persistent modes of exposure, which is consistent with the hypothesis of developing PD through exposure to PQ. Exposure in specific relation to food intake, exposure by water, and under varied environmental conditions where the spatial and temporal demographics of use, water, and soil chemistry requires greater levels of analytical scrutiny to better match environmental conditions to laboratory test.

The physiological science involving laboratory animals, the biochemical hypotheses we reviewed in this paper, and the etiological studies identifying higher probabilities of developing PD following exposure to PQ provides sufficient and necessary evidence to expand the research and solve this problem. However, the environmental context needs to better integrated into the laboratory and vice versa. We suggest expansion of laboratory investigation to match the environmental context and to test animal models, farm animals, or captured wild animals that have been subject to PQ exposure in the environment where PD prevalence has been previously noted concurrent with investigation into the human population. Furthermore, a population-based approach is required where the genetics, expression of phenotype, and ecotoxicology is investigated with an expectation of regional variation in expression of the Parkinsonism phenotype and cultural differences are taken into account, such as different standards of safety for wearing appropriate PPE. Knowing the full extent, rate, and concentration of PQ exposure through multiple routes will improve on experimental procedures into this evasive problem.

\section{ACKNOWLEDGMENTS}

This work was supported by Postdoctoral Research Foundation of Heilongjiang Province of China (LBH-Q12036) and Youth Seeding Foundation of Public Health School, Harbin Medical University of China (no grant number).

\section{DISCLOSURE/CONFLICT OF INTEREST}

The authors declare no conflict of interest. The authors alone are responsible for the content and writing of the paper.

1. Dickson DW. Parkinson's disease and Parkinsonism: neuropathology. Cold Spring Harb Perspect Med 2012;2:a009258.

2. Widerfeldt K, Adami $\mathrm{H}$, Cole $\mathrm{P}$ et al. Epidemiology and etiology of Parkinson's disease: a review of the evidence. Eur J Epidemiol 2011;26:S1-S58.

3. Olanow CW, Tatton WG. Etiology and pathogenesis of Parkinson's disease. Annu Rev Neurosci 1999;22:123-144.

4. Singleton $A B$, Farrer $M$, Johnson J et al. a-Synuclein locus triplication causes Parkinson's disease. Science 2003;302:841.

5. Blesa J, Trigo-Damas I, Quiroga-Varela A et al. Oxidative stress and Parkinson's disease. Front Neuroanat 2015;9:1-9.

6. Dare AJ, Phillips ARJ, Hickey AJR et al. A systematic review of experimental treatments for mitochondrial dysfunction in sepsis and multiple organ dysfunction syndrome. Free Radic Biol Med 2009;47: 1517-1525.

7. Priyadarshi A, Khuder SA, Schaub EA et al. Environmental risk factors and Parkinson's disease: a meta-analysis. Environ Res 2001;86:122-127.

8. Bromilow RH. Paraquat and sustainable agriculture. Pest Manag Sci 2003;60:340-349.

9. Moretto A, Colosio C. Biochemical and toxicological evidence of neurological effects of pesticides: the example of Parkinson's disease. Neurotoxicology 2011;32:383-391.

10. Hilborn R, Stearns SC. On inference in ecology and evolutionary biology: the problem of multiple causes. Acta Biotheor 1982;31: 145-164.

11. Jenkins SH. How Science Works: Evaluating Evidence in Biology and Medicine. Oxford University Press: New York, NY, USA, 2004. 
12. Muthukumaran $\mathrm{K}$, Leahy $\mathrm{S}$, Harrison $\mathrm{K}$ et al. Orally delivered water soluble Coenzyme Q10 (Ubisol-Q10) blocks on-going neurodegeneration in rats exposed to paraquat: potential for therapeutic application in Parkinson's disease. BMC Neurosci 2014;15:21.

13. Jackson-Lewis V, Blesa J, Przedborski S. Animal models of Parkinson's disease. Parkinsonism Rel Disord 2012;18S1:S183-S185.

14. Yin L, Lu L, Prasad K et al. Genetic-based, differential susceptibility to paraquat neurotoxicity in mice. Neurotoxicol Teratol 2011;33:415-421.

15. Shimizu K, Matsubara K, Ohtaki $\mathrm{K}$ et al. Paraquat leads to dopaminergic neural vulnerability in organotypic midbrain culture. Neurosci Res 2003;46:523-532.

16. Pangestiningsigh TW, Wendo WD, Selan YN et al. Histological features of Catecholaminergic neuron in substantia nigra induced by paraquat dichloride (1,1-dimethyl-4,4 bipyridinium) in wistar rat as a model of Parkinson disease. Indones J Biotechnol 2014;19:91-98.

17. Li X, Cheng CM, Sun JL et al. Paraquat induces selective dopaminergic nigrostriatal degeneration in aging C57BL/6 mice. Chin Med J 2005;118:1357-1361.

18. Manning-Bog AB, McCormack $A L$, Li J et al. The herbicide paraquat causes up-regulation and aggregation of alpha-synuclein in mice: paraquat and alpha-synuclein. J Biol Chem 2002;277:1641-1644.

19. Brooks Al, Chadwick CA, Gelbard HA et al. Paraquat elicited neurobehavioural syndrome caused by dopaminergic neuron loss. Brain Res 1999;823:1-10.

20. Zecca L, Gallorini M, Schunemann V et al. Iron, neuromelanin and ferritin content in the substantia nigra of normal subjects at different ages: consequences for iron storage and neurodegenerative processes. J Neurochem 2001;76:1766-1773.

21. Berry C, La Vecchia C, Nicotera P. Paraquat and Parkinson's disease. Cell Death Differ 2010;17:1115-1125.

22. Miller GW. Paraquat: The red herring of Parkinson's disease research. Toxicol Sci 2007;100:1-2.

23. Dauer W, Przedborski S. Parkinson's disease: mechanisms and models. Neuron 2003;39:889-909.

24. McWhite CD, Liebeskind BJ, Marcotte EM. Applications of comparative evolution to human disease genetics. Curr Opin Genetics Dev 2015;35: 16-24.

25. Carlson SD, Juang J, Hilgers SL et al. Blood barriers of the insect. Annu Rev Entomol 2000;45:151-174.

26. Vanitallie TB. Parkinson disease: primacy of age as a risk factor for mitochondrial dysfunction. Metabolism 2008;57:S50-S55.

27. Schapira AH, Cooper JM, Dexter D et al. Mitochondrial complex deficiency in Parkinson's disease. J Neurochem 1990;54:823-827.

28. Cochemé HM, Murphy MP. Complex $\mathrm{I}$ is the major site of mitochondrial superoxide production by paraquat. J Biol Chem 2008;283:1786-1798.

29. Fukushima T, Yamada K, Hojo N et al. Mechanism of cytotoxicity of paraquat III. The effects of acute paraquat exposure on the electron transport system in rat mitochondria. Exp Toxicol Pathol 1994;46: 437-441.

30. Fukushima T, Yamada K, Isobe A et al. Mechanism of cytotoxicity of paraquat. I. NADH oxidation and paraquat radical formation via complex I. Exp Toxicol Pathol 1993;45:345-349.

31. Rodriguez-Rocha H, Garcia-Garcia A, Pickett C et al. Compartmentalized oxidative stress in dopaminergic cell death induced by pesticides and complex I inhibitors: distinct roles of superoxide anion and superoxide dismutases. Free Radic Biol Med 2013;61: 370-383.

32. Bonneh-Barkay D, Reaney SH, Langston WJ et al. Redox cycling of the herbicide paraquat in microglial cultures. Mol Brain Res 2005;134: 52-56.

33. Choi WS, Kruse SE, Palmiter RD et al. Mitochondrial complex I inhibition is not required for dopaminergic neuron death induced by rotenone, MPP+, or paraquat. Proc Natl Acad Sci USA 2008;105:15136-15141.

34. Tawara $\mathrm{T}$, Fukushima $\mathrm{T}$, Hojo $\mathrm{N}$ et al. Effects of paraquat on mitochondrial electron transport system and catecholamine contents in rat brain. Arch Toxicol 1996;70:585-589.

35. Castello PR, Drechsel DA, Patel M. Mitochondria are a major source of paraquat-induced reactive oxygen species production in the brain. J Biol Chem 2007;282:14186-14193.

36. Hosamani R, Muralidhara. Acute exposure of Drosophila melanogaster to paraquat causes oxidative stress and mitochondrial dysfunction. Arch Insect Biochem Physiol 2013;83:25-40.
37. Moretto A, Colosio C. The role of pesticide exposure in the genesis of Parkinson's disease: epidemiological studies and experimental data. Toxicology 2013;307:24-34.

38. Dutheil $\mathrm{F}$, Beaune $\mathrm{P}$, Loriot MA. Xenobiotic metabolizing enzymes in the central nervous system: contribution of cytochrome P450 enzymes in normal and pathological human brain. Biochimie 2008;90: 426-436.

39. Cristovao AC, Choi DH, Baltazar $\mathrm{G}$ et al. The role of NADPH oxidase1derived reactive oxygen species in paraquat-mediated dopaminergic cell death. Antioxid Redox Signal 2009;11:2105-2118.

40. Day BJ, Patel $M$, Calavetta $L$ et al. A mechanism of paraquat toxicity involving nitric oxide synthase. Proc Natl Acad Sci USA 1999;96: $12760-12765$

41. Djukic M, Jovanovic MC, Ninkovic $M$ et al. The role of nitric oxide in paraquat-induced oxidative stress in rat striatum. Ann Agric Environ Med 2007;14:247-252.

42. Ebadi M, Sharma SK. Peroxynitrite and mitochondrial dysfunction in the pathogenesis of Parkinson's disease. Antioxid Redox Signal 2003;5:319-335.

43. Wu XF, Block ML, Zhang $\mathrm{W}$ et al. The role of microglia in paraquatinduced dopaminergic neurotoxicity. Antioxid Redox Signal 2005;7: 654-661.

44. Purisai MG, McCormack AL, Cumine S et al. Microglial activation as a priming event leading to paraquat-induced dopaminergic cell degeneration. Neurobiol Dis 2007;25:392-400.

45. Taetzsch T, Block ML. Pesticides, Microglial NOX2, and Parkinson's disease. J Biochem Mol Toxicol 2013;27:137-149.

46. Lei S, Zavala-Flores L, Garcia-Garcia A et al. Alterations in energy/ redox metabolism induced by mitochondrial and environmental toxins: a specific role for glucose-6-phosphate-dehydrogenase and the pentose phosphate pathway in paraquat toxicity. ACS Chem Biol 2014;9:2032-2048.

47. Naylor JL, Widdowson PS, Simpson MG et al. Further evidence that the blood/brain barrier impedes paraquat entry into the brain. Hum Exp Toxicol 1995;14:587-594.

48. Widdowson PS, Farnworth MJ, Simpson MG et al. Influence of age on the passage of paraquat through the blood-brain barrier in rats: a distribution and pathological examination. Hum Exp Toxicol 1996;15: 231-236.

49. Bartlett RM, Holden JE, Nickles RJ et al. Paraquat is excluded by the blood brain barrier in rhesus macaque: an in vivo pet study. Brain Res 2009;1259:74-79.

50. Lin P, Tseng P. Decreased glial cell line-derived neurotrophic factor levels in patients with depression: a meta-analytic study. J Psychiatr Res 2015;63:20e27.

51. Spindler KR, Hu T. Viral disruption of the blood-brain barrier. Trends Microbiol 2012;20:282-290.

52. Rosenberg GA. Neurological diseases in relation to the blood-brain barrier. J Cereb Blood Flow Metab 2012;32:1139-1151.

53. Cabezas R, Ávila M, Gonzalez J et al. strocytic modulation of blood brain barrier: perspectives on Parkinson's disease. Front Cell Neurosci 2014;8:1-11.

54. Kuter K, Nowak P, Gołembiowska K et al. Increased reactive oxygen species production in the brain after repeated low-dose pesticide paraquat exposure in rats. a comparison with peripheral tissues. Neurochem Res 2010;35:1121-1130.

55. Rappold PM, Cui M, Chesser AS et al. Paraquat neurotoxicity is mediated by the dopamine transporter and organic cation transporter-3. PNAS 2011;108:20766-20771.

56. Bartels AL, Kortekaas R, Bart J et al. Blood-brain barrier P-glycoprotein function decreases in specific brain regions with aging: a possible role in progressive neurodegeneration. Neurobiol Aging 2009;30: $1818-1824$.

57. Dinis-Oliveira RJ, Remião F, Duarte JA et al. P-glycoprotein induction: an antidotal pathway for paraquat-induced lung toxicity. Free Radic Biol Med 2006:41:1213-1224.

58. Prasad K, Winnik B, Thiruchelvam MJ et al. Prolonged toxicokinetics and toxicodynamics of paraquat in mouse brain. Environ Health Perspect 2007;115:1448-1153.

59. Breckenridge $C B$, Sturgess $N C$, Butt $M$ et al. Pharmacokinetic neurochemical, stereological and neuropathological studies on the potential effects of paraquat in the substantia nigra pars compacta and striatum of male C57BL/6 J mice. Neurotoxicology 2013;37:1-14. 
60. Rasad K, Tarasewicz E, Mathew J et al. Toxicokinetics and toxicodynamics of paraquat accumulation in mouse brain. Exp Neurol 2009;215:358-367.

61. Palmada $M$, Centelles JJ. Excitatory amino acid neurotransmission. Pathways for metabolism, storage and reuptake of glutamate in brain. Front Biosci 1998;3:701-718.

62. Mattson MP. Excitotoxic and excitoprotective mechanisms: abundant targets for the prevention and treatment of neurodegenerative disorders. Neuromol Med 2003;3:65-94.

63. Shimizu K, Matsubara K, Ohtaki K et al. Paraquat induces long-lasting dopamine overflow through the excitotoxic pathway in the striatum of freely moving rats. Brain Res 2003;976:243-252.

64. Kang MJ, Gil SJ, Koh HC. Paraquat induces alternation of the dopamine catabolic pathways and glutathione levels in the substantia nigra of mice. Toxicol Lett 2009;188:148-152.

65. Marchitti SA, Deitrich RA, Vasiliou V. Neurotoxicity and metabolism of the catecholamine-derived 3,4-dihydroxyphenylacetaldehyde and 3,4-dihydroxyphenylglycolaldehyde: the role of aldehyde dehydrogenase. Pharmacol Rev 2007;59:125-150.

66. Florang VR, Rees JN, Brogden NK et al. Inhibition of the oxidative metabolism of 3,4-dihydroxyphenylacetaldehyde, a reactive intermediate of dopamine metabolism, by 4-hydroxy-2-nonenal. Neurotoxicology 2007;28:76-82.

67. Chiu C, Yeh T, Lai S et al. Neuroprotective effects of aldehyde dehydrogenase 2 activation in rotenone-induced cellular and animal models of parkinsonism. Exp Neurol 2015;263:244-253.

68. Tomita M, Okuyama T. Effect of paraquat on the malondialdehyde level in rat liver microsomes (in vitro). Arch Toxicol 1994;68:187-192.

69. Chichovska AAM. Effect of paraquat intoxication and ambroxol treatment on hydrogen peroxide production and lipid peroxidation in selected organs of rat. Vet Arhiv 2004;74:141-155.

70. Manning-Bog $A B$, McCormack AL, Purisai MG et al. Alpha-synuclein overexpression protects against paraquat-induced neurodegeneration. J Neurosci 2003;23:3095-3099.

71. Uversky VN, Li J, Fink AL. Pesticides directly accelerate the rate of alpha-synuclein fibril formation: a possible factor in Parkinsons disease. FEBS Lett 2001;500:105-108.

72. Kumar A, Leinisch F, Kadiiska MB et al. Formation and implications of alpha-synuclein radical in maneb- and paraquat-induced models of Parkinson's disease. Mol Neurobiol 2015, [PMID:25952542].

73. Gonzalez-Polo RA, Niso-Santano M, Ortiz-Ortiz MA et al. Relationship between autophagy and apoptotic cell death in human neuroblastoma cells treated with paraquat: could autophagy be a "brake" in paraquat-induced apoptotic death? Autophagy 2007;3:366-367.

74. Gonzalez-Polo RA, Niso-Santano M, Ortiz-Ortiz MA et al. Inhibition of paraquat-induced autophagy accelerates the apoptotic cell death in neuroblastoma SH-SY5Y cells. Toxicol Sci 2007;97:448-458.

75. Garcia-Garcia A, Anandhan A, Burns M et al. Impairment of Atg5dependent autophagic flux promotes paraquat- and MPP+-induced apoptosis but not rotenone or 6-hydroxydopamine toxicity. Toxicol Sci 2013;136:166-182.

76. Niso-Santano M, Bravo-San Pedro JM, Gómez-Sánchez R et al. ASK1 overexpression accelerates paraquat-induced autophagy via endoplasmic reticulum stress. Toxicol Sci 2011;119:156-168.

77. Ara J, Przedborski S, Naini $A B$ et al. Inactivation of tyrosine hydroxylase by nitration following exposure to peroxynitrite and 1methyl-4-phenyl- 1,2,3,6-tetrahydropyridine (MPTP). Proc Natl Acad Sci USA 1998;95:7659-7663.

78. Ren JP, Zhao YW, Sun XJ. Toxic influence of chronic oral administration of paraquat on nigrostriatal dopaminergic neurons in C57BL/6 mice. Chin Med J 2009;122:2366-2371.

79. Kuhn DM, Geddes TJ. Reduced nicotinamide nucleotides prevent nitration of tyrosine hydroxylase by peroxynitrite. Brain Res 2002;933: 85-89.

80. Smith LL. Mechanism of paraquat toxicity in lung and its relevance to treatment. Toxicology 1987;6:31-36.

81. Grillo R, Pereira AE, Nishisaka CS et al. Chitosan/tripolyphosphate nanoparticles loaded with paraquat herbicide: an environmentally safer alternative for weed control. J Hazard Mater 2014;278:163-171.

82. Baltazar MT, Dinis-Oliveira RJ, de Lourdes Bastos M et al. Pesticides exposure as etiological factors of Parkinson's disease and other neurodegenerative diseases - a mechanistic approach. Toxicol Lett 2014;230:85-103.
83. Damanakis M, Drennan DSH, Fryer JD et al. The toxicity of paraquat to a range of species following uptake by the roots. Weed Res 1970;10: 278-283.

84. Slade P. Possible appearance of degradation products of paraquat in crops. Isotopes in Weed Research, Proceedings of a Symposium, 1965 Oct 25-29. pp 113-123. Vienna, Austria.

85. Singh B, Singh K. Microbial degradation of herbicides. Crit Rev Microbiol, print copy in press 2014 Aug. Available from: URL http:// www.tandfonline.com/doi/abs/10.3109/1040841X.2014.929564.

86. Burrows HD, Canle M, Santaballab JA et al. Reaction pathways and mechanisms of photodegradation of pesticides. J Photochem Photobiol B 2002;67:71-108.

87. Florencio $\mathrm{MH}$, Pires $\mathrm{E}$, Castro $\mathrm{AL}$ et al. Photodegradation of Diquat and Paraquat in aqueous solutions by titanium dioxide: evolution of degradation reactions and characterisation of intermediates. Chemosphere 2004;55:345-355.

88. Cantavenera MJ, Catanzaro I, Loddo V et al. Photocatalytic degradation of paraquat and genotoxicity of its intermediate products. J Photochem Photobiol A Chem 2007;185:277-282.

89. Way JM, Newman JF, Moore NW et al. Some ecological effects of the use of paraquat for the control of weeds in small lakes. J App Ecol 1970;8:509-532.

90. Food and Agriculture Organization of the United Nations. FAO Specifications and evaluations for agricultural pesticides: Paraquat dichloride11,1'-dimethyl-4,4'-bipyridinium dichloride 2008.

91. Gondar D, López R, Antelo J et al. Adsorption of paraquat on soil organic matter: effect of exchangeable cations and dissolved organic carbon. J Hazard Mater 2012;235-236:218-223.

92. Morton TG, Ryman J, Assaad A et al. Paraquat dichloride. Human health risk assessment for the request to add uses on perennial tropical and sub-tropical fruit trees. US EPA 2012; P.2012. $14 \mathrm{~A}$.

93. Mbuk RO, Sha'Oto R, Nkpa NN. The role of paraquat (1,1-dimethyl-4,4bipyridinium chloride) and Glyphosate (n-phosphonomethyl glycine) in translocation of metal ions to subsurface soils. Pak J Anal Environ Chem 2015;10:19-24.

94. Santos MSF, Schaule G, Alves A et al. Adsorption of paraquat herbicide on deposits from drinking water networks. Chem Eng J 2013;229:324-333.

95. Van Emon J, Seiber J, Hammock B. Application of an enzyme-linked immunosorbent assay (ELISA) to determine paraquat residues in milk, beef, and potatoes. Bull Environ Contam Toxicol 1987;39:490-497.

96. Ikpesu TO. Effects of agro-chemicals on fishes: With reference to changes in circulating biochemical parameters in Clarias gariepinus induced with paraquat dichloride. Prog Biol Sci 2015;5:111-120.

97. Jones L, Gossett DR, Banks SW et al. Antioxidant defense system in tadpoles of the American bullfrog (Lithobates catesbeianus) exposed to paraquat. J Herpetol 2010;44:222-228.

98. Muangphra P, Kwankua W, Gooneratne R. Genotoxic effects of glyphosate or paraquat on earthworm coelomocytes. Env Toxicol 2014;29:612-620.

99. Eisler R. Paraquat hazards to fish, wildlife, and invertebrates: A synotpic review. US Department of the Interior Fish and Wildlife Service, Biol Rep 1990; 85; Contaminant Hazard Reviews, Report 22.

100. Krůček T, Korandová M, Šerý M et al. Effect of low doses of herbicide paraquat on antioxidant defense in Drosophila. Arch Insect Biochem Physiol 2015;88:235-248.

101. Bortolotto JW, Cognato GP, Christoff RR et al. Long-term exposure to paraquat alters behavioral parameters and dopamine levels in adult zebrafish (Danio rerio). Zebrafish 2014;11:142-153.

102. Ghose SL, Kerby JL, Whitfield SM. Acute toxicity tests and metaanalysis identify gaps in tropical ecotoxicology for amphibians. Env Toxicol Chem 2014;33:2114-2119.

103. Locke KK. Toxicological significance of the following metabolites of paraquat: monoquat, QINA, monopyridone, dipyridone, and methylamine. United States Environmental Protection Agency; 1988 http://archive.epa.gov/pesticides/chemicalsearch/chemical/foia/web/ pdf/061601/061601-1988-09-02a.pdf.

104. Chow AT, Cheung S, Yip PK. Wildlife markets in South China. HumanWildlife Interactions 2014;8:108-112.

105. Jellinger KA. How close are we to revealing the etiology of Parkinson's disease? Expert Rev Neurother 2015;15:1105-1107. 
106. Goldman SM, Kamel F, Ross GW et al. Genetic modification of the association of paraquat and Parkinson's disease. Mov Disord 2012;27: 1652-1658.

107. Semchuk KM, Love EJ, Lee RG. Parkinson's disease: a test of the multifactorial etiological hypothesis. Neurology 1993;43:1173-1180.

108. Carnap R. Logical Foundations of Probability. University of Chicago Press: Chicago, IL, USA, 1950.

109. Cory-Slechta DA, Thiruchelvam M, Di Monte DA. Letter regarding: 'Paraquat: the red herring of Parkinson's disease research'. Toxicol Sci 2008;103:215-216.

110. Alam G, Jones BC. Toxicogenetics: in search of host susceptibility to environmental toxicants. Front Genet 2014;5:1-5.

111. Thrash B, Uthayathas S, Karuppagounder SS et al. Paraquat and maneb induced neurotoxicity. Proc West Pharmacol Soc 2007;50: $31-42$.

112. Tanner CM, Goldman SM, Ross GW et al. The disease intersection of susceptibility and exposure: chemical exposures and neurodegenerative disease risk. Alzheimers Dement 2014;10:S213-S225.

113. Baltazar MT, Dinis-Oliveira RJ, Guilhermino L et al. New formulation of paraquat with lysine acetylsalicylate with low mammalian toxicity and effective herbicidal activity. Pest Manag Sci 2012;69: 553-558.

114. Lee PC, Rhodes SL, Sinsheimer JS et al. Functional paraoxonase 1 variants modify the risk of Parkinson's disease due to organophosphate exposure. Environ Int 2013;56:42-47.

115. Wang A, Cockburn M, Ly $T$ et al. The association between ambient exposure to organophosphates and Parkinson's disease risk. Occup Environ Med 2014;71:275-281.

116. van der Mark M, Vermeulen R, Nijssen PC et al. Occupational exposure to pesticides and endotoxin and Parkinson disease in the Netherlands. Occup Environ Med 2014;71:757-764.

117. Mangano EN, Hayley S. Inflammatory priming of the substantia nigra influences the impact of later paraquat exposure: Neuroimmune sensitization of neurodegeneration. Neurobiol Aging 2009;30: 1361-1378.

118. Ritz BR, Manthripragada AD, Costello $S$ et al. Dopamine transporter genetic variants and pesticides in Parkinson's disease. Environ Health Perpsect 2009;117:964-969.

119. Hindle JV. Ageing, neurodegeneration and Parkinson's disease. Age Ageing 2010;39:156-161.
120. Dinis-Oliveira RJ, Remiao F, Carmo $\mathrm{H}$ et al. Paraquat exposure as an etiological factor of Parkinson's disease. Neurotoxicology 2006;27: 1110-1122.

121. Chung J, Park HR, Lee $S$ et al. Elevated TRAF2/6 expression in Parkinson's disease is caused by the loss of Parkin E3 ligase activity. Lab Invest 2013;93:663-676.

122. Shulman JM, De Jager PL, Feany MB. Parkinson's disease: genetics and pathogenesis. Annu Rev Pathol Mech Dis 2011;6:193-222.

123. Myung $\mathrm{W}$, Lee GH, Won $\mathrm{HH}$ et al. Paraquat prohibition and change in the suicide rate and methods in South Korea. PLoS One 2015;10: e0128980.

124. Yu Y, Guo X, Zhang SL et al. Analysis of paraquat intoxication epidemic (2002-2011) within China. Biomed Environ Sci 2013;26:509-512.

125. Mamane A, Baldi I, Tessier J et al. Occupational exposure to pesticides and respiratory health. Eur Respir Rev 2015;24:306-319.

126. Furlong $M$, Tanner CM, Goldman SM et al. Protective glove use and hygiene habits modify the associations of specific pesticides with Parkinson's disease. Environ Int 2015;75:144-150.

127. Ecobichon DJ. The pesticide dilemma in developing countries. J Sci Tech Human 2003;1:1-9.

128. Wu B, Song B, Tian S et al. Central nervous system damage due to acute paraquat poisoning: a neuroimaging study with $3.0 \mathrm{~T}$ MRI. NeuroToxicol 2012;33:1330-1337.

129. Brent J, Schaeffer TH. Systematic review of parkinsonian syndromes in short- and long-term survivors of paraquat poisoning. J Occup Environ Med 2011;53:1332-1336.

130. Liou HH, Tsai MC, Chen CJ et al. Environmental risk factors and Parkinson's disease: a case control study in Taiwan. Neurology 1997; 48:1583-1588.

131. Pezzoli G, Cereda E. Exposure to pesticides or solvents and risk of Parkinson disease. Neurology 2013;80:2035-2041.

132. Costello S, Cockburn M, Bronstein J et al. Parkinson's disease and residential exposure to maneb and paraquat from agricultural applications in the central valley of California. Am J Epidemiol 2009;169:919-926.

133. Lee PC, Bordelon Y, Bronstein J et al. Traumatic brain injury, paraquat exposure, and their relationship to Parkinson disease. Neurology 2012;79:2061-2066.

134. Goldman SM. Environmental toxins and Parkinson's disease. Annu Rev Pharmacol Toxicol 2014;54:141-164. 